\title{
Distinctly Lonely: How Loneliness at Work Varies by Status in Organizations
}

\begin{abstract}
Purpose: This paper studies the differing pathways to loneliness in managers and their employees. Literatures on emotions in organizational life, organizational management and leadership, and loneliness are explored to develop and test hypotheses regarding the differential prototypical scripts that can be generative of loneliness in managers and employees.
\end{abstract}

Design/methodology/approach: 28 managers and 235 employees from a horticultural company based in Mexico were surveyed, using measures of perceived connection quality, loneliness and meaningful work to test three hypotheses.

Findings: Data from 28 managers and 235 staff indicate that while loneliness scores do not significantly differ between managers and their subordinates, the predictors of loneliness differ between managers and employees, with emotional connection and mutuality predicting loneliness in employees but not in managers.

Originality: This paper adds specification to the literatures on workplace loneliness, the loneliness associated with management roles, emotions in organizational life, and emotions and leadership. The findings are discussed in relation to the literature on manager-subordinate relationships. 
Keywords:

Loneliness; management; emotional connection 
Loneliness, like other emotional states, can have many root causes. In this paper, we will first define loneliness and then examine two particular pathways to loneliness that may differ for managers and employees. These stimuli for loneliness, we will argue, are rooted in distinct 'prototypical scripts' cognitively enacted by managers and employees, respectively. The foundation of this study rests on an emotion taxonomy that links prototypical scripts to subordinate emotions such as loneliness (Fischer, Shaver, \& Carnochan, 1990; Shaver, Schwartz, Kirson, \& O’Connor, 1987). Unfortunately, while the prototypical scriptsloneliness link has been well established (Augoustinos, Walker, \& Donaghue, 2014), the actual cognitive scripts generative of loneliness have been underspecified. More identification of these scripts is therefore necessary in order to better understand the social construction of loneliness by organizational actors.

This paper adds specification to the literatures on loneliness (Cacioppo, Grippo, London, Goossens, \& Cacioppo, 2015; Firoz \& Chaudhary, 2021; Firoz, Chaudhary \& Khan, 2020; Heinrich \& Gullone, 2006; Wright \& Silard, 2020), the loneliness associated with management roles (Ashman \& Lawler, 2008; Carpenter, 2007; Chen, Wen, Peng, \& Liu, 2016; Collinson, 2005; Davenport, 2015; Methot, LePine, Podsakoff, \& Christian, 2016; Zumaeta, 2019), emotions in organizational life (Ciftci, 2021; Wegge, Van Dick, \& von Bernstorff, 2010; see Ashkanasy \& Humphrey, 2011; Barsade \& Gibson, 2007 for reviews), and emotions and leadership (Humphrey, Pollack, \& Hawver, 2008; Jung, Song \& Yoon, 2021; for reviews, see Gooty, Connelly, Griffith, \& Gupta, 2010; Rajah, Song, \& Arvey, 2011). This objective is accomplished by uncovering specific prototypical scripts—namely the need for emotional connection and the need for meaningfulness- that are differentially generative of loneliness for managers and employees, respectively.

\section{Defining Loneliness and its Outcomes in Organizational Life}


Loneliness has been defined as a negative transient emotion (Qualter et al., 2015) or "subjective emotional state" (Holt-Lunstad, Smith, Baker, Harris, \& Stephenson, 2015, p. 228) associated with an individual's subjective perception of social isolation. Loneliness, hence, is a distressing reaction to an individual's perceived deficiency in social relationships or their perceived absence of closeness, emotionality, and authenticity in their relationships (Masi, Chen, Hawkley \& Cacioppo, 2011). The experience of loneliness is distinct from actual social isolation, which can be objectively identified as an individual's peripheral location in relation to their social network (Holt-Lunstad et al., 2015).

Loneliness is an important phenomenon in organizational life for employees (Jung, Song \& Yoon, 2021; Wright \& Silard, 2020) and leaders (Gabriel, Lanai \& Jennings, 2020; Kuna, 2019), and can lead to detrimental physiological and psychological outcomes, as well as potential unfavorable organizational outcomes (Hawkley et al., 2008; Ozcelik \& Barsade, 2018). While solitude can generate benefits for individuals such as enhanced creativity, selfregulation, and concentration, and identity formation (Heinrich \& Gullone, 2006; Winnicott, 1960), loneliness almost always produces deleterious outcomes at multiple levels (Cacioppo, Chen, \& Cacioppo, 2017). Physical effects of loneliness include higher risk of mortality (House, Landis, \& Umberson, 1988) and less effective physiological repair mechanisms (Cacioppo \& Hawkley, 2003). The adverse psychological correlates of loneliness are also plentiful, such as decreased self-control (Williams, Cheung, \& Choi, 2000), self-esteem (Leary, Tambor, Terdal, \& Downs, 1995), increased anxiety (Baumeister \& Tice, 1990), reduced job-related well-being (Erdil \& Ertosun, 2011), reduced creativity in the workplace (Peng, Chen, Xia, \& Ran, 2017), and burnout among managers (Cubitt \& Burt, 2002). Looking at these outcomes, loneliness might appear to be a quintessential individualistic experience; however, it is also a function of the individual's larger social network (Cacioppo, Fowler, \& Christakis, 2009). 
While studying the implications of loneliness in an organization's social network is beyond the scope of this study, the finding that loneliness can propagate in a social network has implications for how its experience in an organization is understood. When people feel lonely they tend to exhibit socially negative behavior (e.g. hostility and defensiveness) which may impede their capacity to perform emotional labor and develop necessary workplace relationships (Humphrey et al., 2008). These behaviors may lower the relationship satisfaction of fellow employees. As such, if managers are feeling lonely in their role and generally do not feel emotionally connected to others, this emotion can affect subordinates. Additionally, if feelings of loneliness stem from one's followers this can be a powerful relational signal for leaders that affects their ability to perform their role effectively (Gabriel, Lanai \& Jennings, 2020).

The unfavorable potential organizational outcomes associated with manager and employee loneliness are therefore worrisome, as lonely individuals experience diminished executive functioning and lower performance on complex cognitive tasks such as the abstract thinking required for innovation, planning, and decision making (Cacioppo \& Patrick, 2008). Consequently, lonely individuals are less likely to use good judgment in making decisions (Cacioppo, Grippo, London, Goossens, \& Cacioppo, 2015).

\section{Emotional Connection among Managers and Employees in Organizations}

Many individuals join organizations in order to belong to groups, a vital step necessary for survival, as groups are better at acquiring resources than individuals and offer a level of protection that individuals cannot match (Baumeister \& Leary, 1995). Hence, affectively connecting with others in a social group may be a primary reason most individuals join organizations. However one's position in the organization may affect the quality of those relationships. For example, manager daily interactions with followers may not generate the 
same level of closeness as peer-to-peer workplace relationships (e.g., Methot, LePine, Podsakoff, \& Christian, 2016), given the heightened status- and power-related distance typically associated with positions of leadership (Anicich \& Hirsh, 2017; Zumaeta, 2019). Instead leaders may feel loneliness stemming from relationships with followers.

In organizational life, high 'connection quality' has been defined as a mutually experienced dyadic positive emotional state of relatedness (Silard \& Watson-Manheim, 2015). This definition is rooted in Dutton \& Heaphy's (2003) construction of high-quality connections, which are concerned with "short-term, dyadic interactions that are positive in terms of the subjective experience of the connected individuals" (Stephens, Heaphy, \& Dutton, 2011, p. 3). High connection quality is a member of the constellation of positive emotions described by emotion theorists (e.g., Fredrickson, 1998; Larsen \& Diener, 1992; Russell, 1980, 2003).

It follows that the quality of connection with others is logically linked to loneliness, as a failure to experience meaning can be perceived by the individual as a distressing gap between their desired and actual social relationships (Tam \& Chan, 2019). The negative emotions associated with this perception have generally been defined as loneliness (Qualter et al., 2015; Silard \& Wright, 2020). A prototypical script that may be generative of loneliness in organizations, hence, may be the cognitive perception of a lack of emotion-imbued connections with other organizational actors.

A failure to achieve sufficient levels of connection may be highly negatively construed by organizational members, leading to the emotional state of loneliness. In fact, it has been suggested that a lack of high-quality connections between organizational actors is likely to be energy depleting (Dutton \& Heaphy, 2003) and lead to relationship deficiencies (Colbert, Bono, \& Purvanova, 2015) and lower identification with the organization (Stephens 
et al., 2011); a toxic combination that could feasibly engender a distressing emotional state associated with a perceived scarcity of social resources, or loneliness. Further, a field study of 161 call center representatives found that emotional dissonance is associated with reduced employee well-being and work motivation, the expression of negative affect, and counterproductive work behaviors (Wegge et al., 2010). The opposite of emotional dissonance is emotional resonance, a likely correlate of a strong emotional connection. As such, emotional dissonance is likely linked to a weak emotional connection and loneliness.

While the perception of high-quality relationships with coworkers may be highly prioritized and desirable for staff, the same may not be true for managers or leaders (Gabriel, Lanaj, \& Jennings, 2020). In fact, the very cognitive schemas managers possess in relation to how a manager should behave (Lord \& Maher, 1991; Lord, 1985), including those related to the level of detachment managers should maintain from employees (Collinson, 2005), may suggest to them that they should keep a professional distance from their employees in order to maintain social control (Antonakis \& Atwater, 2002). These internal information processing theories of leadership may result in not only a low level of actual relationships with their team members, but also a low level of desired relationships. In this case, the perceived deficiency (desired minus actual) would be small, suggesting a negligible experience of loneliness generated by the need-to-connect prototypical script.

Research from Waytz, Chou, Magee, \& Galinsky (2015) suggests that personal power increases self-sufficiency and the desire to perform tasks alone, but lacking power augments the desire for social connection. As such, employees need for intra-organizational interpersonal relationships may be stronger than is this need for managers. Managers also possess extensive social networks external to the organization because of their high levels of status (Waytz, Chou, Magee, \& Galinsky, 2015). Therefore, it may also be possible that 
managers emphasize connecting with their employees less because managers have valuable connections outside the organization, and wish to maintain social distance from their employees. Hence, it may be possible that the prototypical script leading to loneliness stemming from low perceived connection quality may be more salient for employees than for managers.

Hypothesis 1A: Employees experience higher perceived connection quality in organizations than managers.

Hypothesis 1B: Low perceived connection quality is predictive of employee loneliness but is not predictive of manager loneliness.

\section{Meaningfulness among Managers and Employees in Organizations}

Meaningfulness has been conceptualized as a cognitive and affective assessment an individual makes as to whether their life has purpose and value (Baumeister, Vohs, Aaker, \& Garbinsky, 2012; Borawski, Siudak, Pawelec, Rozpara \& Zawada, 2021). In an organizational context, when an actor experiences meaningfulness, they are likely to feel "worthwhile, useful, and valuable• as though they made a difference and were not taken for granted......able to give to others and to the work itself in their roles and also able to receive" (Kahn, 1990, p. 704). The idea of individual workers searching for meaning through need fulfilment is not a new phenomenon, with Maslow (1971) suggesting that employees who do not find their work meaningful will not perform at their best. However, the link between relational need fulfilment at work (Ryan \& Deci, 2002), meaningfulness and workplace loneliness is less understood.

Research by Lips-Wiersma, Wright \& Dik (2016) suggests that managers, supervisors, and business owners place more importance on meaning in their work than those in lower-status roles. While the need to make a meaningful contribution in one's managerial 
career is therefore important, its lack of fulfillment in a managerial role may also be linked to loneliness. An individual who does not feel this need is satisfied may experience a perceived scarcity of social resources for two primary reasons. First, if the need to make a meaningful contribution is strong for an individual and they feel they cannot meet this need in an organization, they may be uncertain of how long they will stay in their current job and consequently may make less effort to develop high-quality connections with their coworkers. Second, if they do not deem the organizational mission meaningful, they may not hold other organizational members in high esteem (as they may perceive such members to be wasting their time working for an organization devoid of social purpose). Consequently, they may not wish to form relationships with such values-incongruent individuals. In both cases, the lack of meaningfulness they experience at work may lead to a perceived scarcity of social resources. That is, they wish they had more high-quality relationships with value-congruent others, but do not experience such relationships in the organization, which, if distressing to the individual, manifests as loneliness (Qualter et al., 2015; Silard \& Wright, 2020). A prototypical script that may be generative of loneliness in organizations, hence, may be the cognitive perception of a lack of meaningfulness associated with one's work.

Managers have often been considered "meaning makers" that are charged with the daunting task of motivating employees through the articulation of a strong sense of purpose (Bass, 1985; Conger \& Kanungo, 1987) or an inspirational vision of the future (Johnson, 2008; Menges, Walter, Vogel, \& Bruch, 2011; Sosik \& Dinger, 2007). More often than not, this manager messaging is delivered as a persuasive appeal to shared values (Selznick, 1957) ultimately designed by managers to convince employees to alter their attitudes or behavior (Bass, 1985; Shamir et al., 1993). The strength of this appeal is critical, as a manager's failure to enable organizational actors to create socially constructed meaning associated with the organizational purpose tends to produce unfavorable outcomes such as lack of commitment 
and employee cynicism (Cartwright \& Holmes, 2006). In order to rise to this Herculean challenge, managers must find meaning themselves in their work, which requires a search for self-realization through deep communication with themselves and employees (Ashman \& Lawler, 2008) that becomes challenging when managers attempt to "avoid loneliness at any price" (p. 257). This task is all the more challenging given the myriad responsibilities of their roles (Mintzberg, 1973) that leave little time for their own social construction of meaningfulness associated with the organizational mission.

In addition to socially constructing a sense of meaning associated with the organizational purpose, it is important for managers to experience meaningfulness as they are the organizational actors most tasked with giving to others-a core element of meaningfulness (Kahn, 1990)—through providing individualized consideration (a core element of transformational leadership; Avolio, Waldman, \& Yammarino, 1991) and empathy to employees, even when such emotion helping is unreciprocated (Toegel, Kilduff, \& Anand, 2013).

Hence, given the nature of the managerial role, it seems likely that individuals that seek meaningfulness in their work will gravitate more toward managerial roles than individuals for whom such work-imbued meaningfulness is less important. In fact, information processing theories of leadership suggest that the mere expectation that most individuals have that managers must inspire and motivate employees through their communication of the organizational purpose (Lord \& Maher, 1991; Lord, 1985) would impede individuals who find it difficult to encounter and convey such meaning within an organization from aspiring to a managerial role. This theorizing leads to the hypothesis that the prototypical script leading to loneliness due to a lack of meaningfulness associated with one's work may be more salient for managers than for employees. 
Hypothesis 2A: Managers experience higher meaningfulness in organizations than employees.

Hypothesis 2B: Lack of meaning experienced in organizations is predictive of manager loneliness but is not predictive of employee loneliness.

\section{Manager and Employee Levels of Loneliness}

The third contention is that, given the divergent prototypical scripts that are generative of manager and employee loneliness, respectively, it is likely that the actual level of loneliness that high- and low-status organizational actors experience is relatively similar, yet for different reasons. In other words, the divergent prototypical scripts each produce similar levels of loneliness, with low perceived connection quality generating employee loneliness and lack of meaningfulness generating manager loneliness.

Research has suggested that the 'lonely at the top' adage possesses more anecdotal appeal than empirical support. A study by Wright (2012) found that across three organizations and multiple loneliness measures, there was no discernible difference in manager and employee levels of loneliness, either at work or in their personal lives. Additional empirical research has found that managers and their employees experience higher LMX when both feel similar levels of loneliness, and this level of LMX rises as manageremployee-congruent levels of loneliness fall (Chen et al., 2016).

Additionally, other research suggests that managers tend to experience less loneliness than other occupational groups, such as technical, sales, and clerical staff (Bell, Roloff, Van Camp, \& Karol, 1990; Page \& Cole, 1991).These findings are attributed to people at higher organizational levels differing from lower-status employees on individual or interpersonal dimensions—such as social skills, marital satisfaction and interpersonal orientation—that may shield them from loneliness (Bell et al., 1990; Page \& Cole, 1991). The purpose of the 
current study is to acknowledge this prior research on the challenge to the 'lonely at the top' adage, and lay the beginnings of an empirical foundation for understanding the differing antecedents of loneliness at different levels of the organization.

Therefore, the third hypothesis is that, for some managers, the loneliness they may experience is identified due to a lack of meaningfulness in their work that they seek. Yet it is possible that it can be equally lonely at the bottom, for the distinct reason that employees often do not make the social connections they desire. In terms of general loneliness, no manager-employee difference is predicted.

Hypothesis 3: Managers and employees experience similar levels of loneliness.

\section{Method}

\section{Participants and procedure}

The participants all worked for a horticultural greenhouse organization in central Mexico. This company primarily exports tomatoes to the US market. As part of their participation in a strategic planning retreat and a management training exercise facilitated by the first author, managers were invited to complete a confidential survey for research purposes. Managers were also asked to distribute the survey to their direct reports in the organization (who did not have any managerial responsibilities themselves). Completed employee surveys were sent directly to the researchers, thus the data could not be seen by the managers. The respondents were informed that the organization was interested in further understanding management and organizational dynamics. They were also informed that their individual responses would be kept confidential and would only be seen by the researchers, and that only aggregated results would be reported back to the organization. 
The data gathering exercise generated responses from 28 managers and 235 employees in the organization, representing response rates of $100 \%$ and $78 \%$, respectively. In keeping with the demographic makeup of most organizations, where $70 \%$ of managers are men (including data from Mexico; Boatman, Wellins, \& Neal, 2011), eighty two percent of the managers in the current study were men, their average age was 30.2 years $(\mathrm{SD}=9.8$ years), they had an average tenure of 2.3 years in their current position ( $\mathrm{SD}=1.6$ years) and 2.7 years in the organization $(\mathrm{SD}=2.3$ years). Fifty three percent of the employees were men and $45 \%$ were women ( $2 \%$ did not provide gender). Their average age was 25.5 years $(\mathrm{SD}=$ 10.2 years). They had an average tenure of 1.3 years in their current position ( $\mathrm{SD}=1.6$ years) and 2.1 years $(\mathrm{SD}=1.2$ years $)$ in the organization.

\section{Measures}

Unless otherwise stated, all of the items on the survey were responded to on a 5-point Likert scale. The anchors for the scale were strongly disagree (1) to strongly agree (5). The items in the scales were averaged to create an overall mean for each variable. The items were coded such that a high value represents a high level of the particular construct.

\section{Perceived Connection Quality (Mutuality; Positive Regard; Emotional}

Connection). This study is primarily concerned with measuring managers' and employees' perceptions of subjective, affective relationship experiences. The orientation toward understanding subjective experiences aligns with the conception of loneliness as the emotional distress associated with perceived interpersonal disconnection. Perceptions of connection quality were measured using Dutton \& Heaphy's (2003; Stephens, Dutton and Heaphy, 2011) concept of 'mutuality' and 'positive regard'. Mutuality is defined as conjointly experienced vulnerability and responsiveness as both people fully participate and engage in the connection. This construct was measured using four items (current study $\bullet=$ 
.76; "The relationship between those I work with and myself is based on mutuality", "We are committed to one another at work", "There is a sense of empathy between my coworkers/those I supervise and myself", "I feel that the people I work with do things for one another"). Positive regard is defined as feeling known, or being respected and cared for. This was measured using three items (current study • = .67; "I feel liked in my workplace", "I feel that my co-workers and I try to develop meaningful relationships with one another", "I feel understood in my workplace") (Carmeli, Brueller, \& Dutton, 2009). The structural features of high-quality connections (emotional carrying capacity, tensility and connectivity) were not included in this study because of the primary concern with the individuals' perception of subjective connection experiences.

As part of perceived connection quality, the study investigated the emotional connection managers and employees experienced with others in their work environment. 'Emotional connection' items were adapted from a widely used and previously validated loneliness scale (R-UCLA; Russell, Peplau, \& Cutrona, 1980). Some of the items commonly used to measure loneliness actually measure emotional connection to others as an antecedent to loneliness, with several items depicting the quality of emotional connection with others. Four items were isolated and included as an antecedent to loneliness. The items were phrased so they were appropriate to the work environment (phrasing shown in italics). The items were: "The relationships I have with the people I work with are more superficial than I would like them to be (reversed)," "I am no longer close to anyone at work (reversed)," "I feel emotionally connected with some of the people I work with," "I have meaningful relationships with some of the people I work with." (current study $\bullet=.72$ )

The specific effects these variables had on loneliness were analyzed as individual constructs (mutuality, positive regard, and emotional connection) rather than aggregating 
them as one perceived connection quality score. Exploratory factor analyses using oblique rotation for the three perceived connection quality variables indicate a simple structure (eigenvalues $3.7,1.4,1.2$ ). Items loaded onto the three respective factors and there were no cross loadings above .20 (mutuality .71 .60 .78, .82; positive regard .72, .70, .73; emotional connection $.69, .79, .73, .78)$.

Meaningfulness at Work. Meaningfulness of work was measured with the 3-item scale (current study $\bullet=.82$ ) developed by Spreitzer (1995). The three items were "The work I do is very important to me," "My job activities are personally meaningful to me," and "The work I do is meaningful to me."

Loneliness. Loneliness was measured using the ULS-4 (Russell et al., 1980, p. 474; current study $\bullet=.72$ ), a short form of the 20-item R-UCLA loneliness scale (Russell et al., 1980) and adapted for the work environment. Items were measured on a 4-point Likert scale: never, rarely, sometimes, often. The fours items were "I feel in tune with people around me $a t$ work (reversed)," "No one really knows me well at work," "I can find companionship at work when I want to (reversed)," and "People are around me but not with me at work."

\section{Results}

Welch's $t$-tests were conducted to test group differences between managers and employees for perceived connection quality, meaningfulness, and loneliness. Welch's test was used due to the unequal sizes between the manager group and employee group (Delacre, Lakens \& Leys, 2017). Cohen's d and confidence internals were calculated to explore the magnitude of difference between managers and employees. Linear regression analyses were conducted to test the predictive values of perceived connection quality and meaningfulness onto loneliness. 
Hla concerned the differing degrees of perceived connection quality between managers and employees. Table 1 shows the means and standard deviations for the study variables. The data indicates a mix of results for this hypothesis. As expected, emotional connection was higher for employees than managers with a large magnitude of difference $\left(t(261)=8.72, p=.<.001 ; \eta^{2}=1.4,95 \%\right.$ CI $\left.1.06-1.89\right)$. However, interestingly, mutuality was higher for managers than employees $\left(t(42)=3.00, p<.05 ; \eta^{2}=.50,95 \%\right.$ CI $\left..11-.89\right)$. Levene's test indicated unequal variances $(F=4.59, p=.03)$ for mutuality, therefore the degrees of freedom were adjusted from 261 to 42. Positive regard was also higher for managers than employees $\left(t(261)=2.90, p<.01 ; \eta^{2}=.57,95 \% \mathrm{CI} .18-.97\right) . H 1 a$ is therefore partially supported in that perceived connection quality is higher for employees than managers with regards to emotional connection, but managers have higher levels of mutuality and positive regard than employees.

$H 2 a$ concerned the differences in the experience of meaningfulness at work between managers and employees (see Table 1). The data supports hypothesis $2 a$, in that managers experience more meaning in their work than employees $\left(t(34)=4.12, p<.01 ; \eta^{2}=.83,95 \% \mathrm{CI}\right.$ $.44-1.23)$. Levene's test indicated unequal variances $(F=5.67, p=.02)$, therefore degrees of freedom were adjusted from 261 to 34 . Cohen's effect size value suggests a moderate magnitude of difference between managers and employees' meaningfulness scores.

Correlation analyses were conducted between the study variables (Tables $2 \& 3$ ) and regression analyses in order to examine the influence of the perceived connection quality variables and meaningfulness on loneliness $(H 1 b$ and $H 2 b$; see Table 4$)$. Hypothesis $1 b$ predicted that perceived connection quality scores would predict loneliness in employees, but not managers. This hypothesis was partially supported for employees, in that emotional connection and mutuality predicted loneliness, but could not be substantiated for managers as 
the manager regression model was non-significant $(p=.11)$. This disparity could be due to the lower sample size of managers in reducing the probability of finding significant results in the sample. Hypothesis $2 b$ is therefore partially supported in that a lack of work meaningfulness did not predict loneliness in employees, but cannot be determined for managers due to the non-significant manager regression model.

As expected, Welch's t-test results show no difference in loneliness scores between employees and managers. To be assured this result was not due to uneven sample sizes, the employee group data was randomly assigned into nine smaller groups and each tested against the manager group. All t-test results showed no difference in loneliness scores therefore supporting hypothesis 3 .

\section{Discussion}

The purpose of this research was to identify any differences between managers and employees in the prototypical scripts that may be generative of loneliness; with a view to providing initial data to begin understanding these differences. This study supports previous research (Wright, 2012) that loneliness scores do not significantly differ between managers and employees. The remaining analyses produced mixed results. As expected, emotion connection was much higher for employees than managers indicating that employees experience emotional connection with others in the workplace more readily than managers do. However, managers have higher levels of mutuality and positive regard with those they work with. Because of their role and position in the organization, managers may experience positive regard from employees through a sense of feeling known and/or being respected by others. This study suggests that such a feeling is not experienced by subordinates in the same way managers experience it. The current study has found that managers experience more mutuality, for instance, in their connections with others (in terms of participation and 
engagement with others). This finding could also be role-based, in that those in lower-status roles do not have as much autonomy in their roles to actively participate in relationship connections (Lips-Wiersma et al., 2016; Wang \& Liu, 2020).

Previous research suggests that loneliness is a growing concern in the general population as it relates to negative health outcomes (Silard; 2020; Rico-Uribe et al., 2016). Concurrently, the idea of a socially cohesive work environment is often devalued in organizations (Bolman \& Deal, 1997). Therefore, the low overall means in this study may represent a measurement issue rather than loneliness itself not being a 'real' issue. However, further conceptual, qualitative, and psychometric work is needed to explore these ideas.

Considering that poor quality relationships are a significant influencer of loneliness (Gierveld, Tilburg, \& Dykstra, 2006) and friendships are an important predictor of life satisfaction (Li \& Kanazawa, 2016), most loneliness studies emphasize the importance of meaningful relationship development as a buffer against loneliness. The development of the emotional connection aspect of connection quality within organizations, which are associated with a high level of trust and mutuality (Dutton \& Heaphy, 2003) might therefore be the best antidote to loneliness. The current study suggests that this statement may be more evident for employees than managers. The analyses reveal a preliminary pattern in how work connections and loneliness are experienced by managers and employees. Interestingly, a lack of emotional connection and mutuality were predictive of loneliness in employees but none of the perceived connection quality measures predicted loneliness in managers. However, caution is required about over-interpreting the non-significant findings for predicting loneliness in managers considering that a smaller sample of managers were surveyed than employees.

While it is common to have a smaller number of managers than employees in an organization, and for there to be more male than female managers (Boatman, Wellins, \& 
Neal, 2011a), it would be helpful to expand this research to a greater number of managers and employees both in other organizations and in other countries. Although an exhaustive sample from one organization was used for this study, future research on managerial loneliness will help substantiate or refute the stability of these findings.

Nonetheless, the findings of this study do suggest that the emotional nutrition found within high-quality connections could be an antidote for loneliness in employees. It is telling that the two surviving predictors of loneliness for employees were emotional connection and mutuality, both of which represent a fundamental desire for social intimacy, interpersonal reciprocity, and meaningful interpersonal connection. This phenomenon is likely operationalized by the role of emotional connection and mutuality as the basis of connection quality (Dutton \& Heaphy, 2003), a lack of which is at the heart of feeling lonely (Heinrich \& Gullone, 2006). The current research, although based on a small sample, suggests a need to look more closely at the predictors of loneliness across different levels in the organization, and in particular a focus on connection quality between employees.

In terms of interventions for loneliness, actions can be directly related to the core manifestation of the problem through the provision of individual assistance. Alternatively, such interventions can be approached indirectly, such as attending to the nature of the social climate of the organization. It has been argued that work-related stress is most effectively managed by work-related sources of support because the stress treatment occurs in the context of the stressful situation (Beehr, 1985). Therefore, attending to the work environment, rather than remedying personal factors, may help to prevent or reduce feelings of loneliness at work. As such, organizational interventions may help to create a healthy work climate by attending to organizational values which instill positive social relations and emphasize a sense of belonging. In this respect, establishing appropriate social norms can help orient organizational members toward the kinds of behaviors that will lead to a climate of trust, 
belonging, and shared values. These behaviors could include, for example, encouraging peer support collaborations or providing social spaces for work breaks. Such norms are contingent upon an overall structure and environment whereby organizational members are permitted to develop various social opportunities and, consequently, to expend their social resources.

Managers, this study has found, come to organizations finding more meaningfulness in their work role than do employees. This finding supports previous research regarding higher status workers experiencing greater meaning in their work (Lips-Wiersma et al., 2016). This finding also contributes to research on manager-employee relationships, especially relationship-oriented theories such as LMX (Graen \& Uhl-Bien, 1995), transformational leadership (Bass, 1985; Yammarino, Spangler, \& Bass, 1993), and authentic leadership (Gardner, Avolio, Luthans, May, \& Walumbwa, 2005) by suggesting that when managers develop high-quality connections with employees, it may be primarily to benefit employees rather than the managers themselves. Future theoretical and empirical research on manager loneliness is needed to understand this tentative finding. Such theorizing, is consonant with research that has found that relationship-oriented managerial behaviors such as empathy are not reciprocated by employees (Toegel et al., 2013).

In terms of future research, it may be the case that managers develop relationships with employees not because they intrinsically benefit from such relationships, but because the development of such relationships helps managers to find meaning in their work. For example, spurring employee development and helping employees grow in their careers, a common behavior of humble leaders (Owens \& Hekman, 2012), may help managers to derive meaning from their roles, which is potentially why managers in the current study enacted higher positive regard and mutuality than employees. An understanding of employee loneliness may also help managers to experience more compassion and empathy toward and develop higher-quality connections amongst employees (Davenport, 2015). It is our hope that 
this study will provide a useful impetus for future research that might further elaborate on how the experience or expectation of loneliness influences manager motivations in relation to the development of meaningful relationships. 


\section{References}

Antonakis, J., \& Atwater, L. (2002). Leader distance: A review and a proposed theory. Leadership Quarterly, 13, 673-704.

Ashkanasy, N. M., \& Humphrey, R. H. R. (2011). Current emotion research in organizational behavior. Emotion Review, 3(2), 214-224.

Ashman, I., \& Lawler, J. (2008). Existential Communication and Leadership. Leadership, $4(3), 253-269$.

Augoustinos, M., Walker, I., \& Donaghue, N. (2014). Social cognition: An integrated introduction. Sage Publications.

Avolio, B. J., Waldman, D. A., \& Yammarino, F. J. (1991). Leading in the 1990s: The four I's of transformational leadership. Journal of European Industrial Training, 15(4).

Barsade, S. G., \& Gibson, D. E. (2007). Why Does Affect Matter in Organizations? Academy of Management Perspectives, 21(1), 36-59.

Bass, B. M. (1985). Leadership and performance beyond expectations. New York, NY: Free Press.

Baumeister, R. F., \& Leary, M. (1995). The need to belong: desire for interpersonal attachments as a fundamental human motivation. Psychological Bulletin, 117(3), 497529.

Baumeister, R. F., \& Tice, D. M. (1990). Point-counterpoints: Anxiety and social exclusion. Journal of Social and Clinical Psychology, 9(2), 165-195.

Baumeister, R. F., Vohs, K., Aaker, J. L., \& Garbinsky, E. N. (2012). Some key differences between a happy life and a meaningful life. Journal of Positive Psychology, 1-22.

Beehr, T. (1985). The role of social support in coping with organizational stress. In T. Beehr \& R. Bhagat (Eds.), Human stress and cognition in organizations: An integrated perspective (pp. 375-398). New York: Wiley.

Bell, R. A., Roloff, M. E., Van Camp, K., \& Karol, S. H. (1990). Is it lonely at the top? Career success and personal relationships. Journal of Communication, 40(1), 9-23.

Boatman, J., Wellins, R., \& Neal, S. (2011a). Women work: The business benefits of closing the gender gap. Global Leadership Forecast. Retrieved from https://www.ddiworld.com/ddi/media/trendresearch/womenatworkgendergap_br_ddi.pdf

Boatman, J., Wellins, R. S., \& Neal, S. (2011b). Global leadership forecast 2011: Time for a leadership revolution. Bridgeville, PA: Development Dimensions International.

Bolman, L. G., \& Deal, T. E. (1997). Reframing organizations. San Francisco: Jossey-Bass.

Borawski, D., Siudak, A., Pawelec, A., Rozpara, B., \& Zawada, M. (2021). The interplay between loneliness, mindfulness, and presence of meaning. does search for meaning matter? Personality and Individual Differences, 172,

Cacioppo, J., Fowler, J., \& Christakis, N. (2009). Alone in the crowd: The structure and 
spread of loneliness in a large social network. Journal of Personality and Social Psychology, 97(6), 977-991.

Cacioppo, J., \& Hawkley, L. (2003). Social isolation and health, with an emphasis on underlying mechanisms. Perspectives in Biology and Medicine, 46(3), S39-S52.

Cacioppo, J. T., Chen, H. Y., \& Cacioppo, S. (2017). Reciprocal Influences Between Loneliness and Self-Centeredness: A Cross-Lagged Panel Analysis in a PopulationBased Sample of African American, Hispanic, and Caucasian Adults. Personality and Social Psychology Bulletin, 43(8), 1125-1135.

Cacioppo, J. T., \& Patrick, W. (2008). Loneliness: Human nature and the need for social connection. New York: WW Norton \& Company.

Cacioppo, S., Grippo, A. J., London, S., Goossens, L., \& Cacioppo, J. T. (2015). Loneliness: Clinical import and interventions. Perspectives on Psychological Science, 10(2), 238249.

Carmeli, A., Brueller, D., \& Dutton, J. E. (2009). Learning behaviours in the workplace: The role of high-quality interpersonal relationships and psychological safety. Systems Research and Behavioral Science, 98(November 2008), 81-98.

Carpenter, D. M. I. (2007). Presidents of the United States on Leadership. Leadership, $3(1993), 251-280$.

Cartwright, S., \& Holmes, N. (2006). The meaning of work: The challenge of regaining employee engagement and reducing cynicism. Human Resource Management Review, 16(2), 199-208.

Chen, Y., Wen, Z., Peng, J., \& Liu, X. (2016). Leader-follower congruence in loneliness, LMX and turnover intention. Journal of Managerial Psychology. Journal of Managerial Psychology, 31(4), 864-879.

Colbert, A. E., Bono, J. E., \& Purvanova, R. K. (2015). Flourishing via workplace relationships: Moving beyond instrumental support. Academy of Management Journal.

Collinson, D. (2005). Questions of Distance. Leadership, 1(2), 235-250.

Conger, J., \& Kanungo, R. (1987). Toward a behavioral theory of charismatic leadership in organizational settings. Academy of Management Review, 12(4), 637-647.

Ç•FTC•, D. Ö. (2021). Emotional exhaustion as a mediator among workplace loneliness, work alienation and turnover intention. International Journal of Organization Theory \& Behavior.

Cubitt, S., \& Burt, C. (2002). Leadership style, loneliness and occupational stress in New Zealand primary school principals. New Zealand Journal of Educational Studies, 37(2), $159-169$.

Davenport, B. (2015). Compassion, suffering and servant-leadership: Combining compassion and servant-leadership to respond to suffering. Leadership, 11(3), 300-315.

Delacre, M., Lakens, D., \& Leys, C. (2017). Why psychologists should by default use Welch's t-test instead of Student's t-test. International Review of Social 
Psychology, 30(1).

Dutton, J., \& Heaphy, E. (2003). The power of high-quality connections. In Positive organizational scholarship: Foundations of a new discipline (3rd ed., pp. 263-278).

Erdil, O., \& Ertosun, Ö. G. (2011). The relationship between social climate and loneliness in the workplace and effects on employee well-being. Procedia-Social and Behavioral Sciences, 24, 505-525.

Fischer, K. W., Shaver, P. R., \& Carnochan, P. (1990). How emotions develop and how they organise development. Cognition \& Emotion, 4(2), 81-127.

Firoz, M., \& Chaudhary, R. (2021). The impact of workplace loneliness on employee outcomes: what role does psychological capital play?. Personnel Review.

Firoz, M., Chaudhary, R., \& Khan, A. (2020). Desolated milieu: exploring the trajectory of workplace loneliness (2006-2019). Management Research Review

Fredrickson, B. L. (1998). What good are positive emotions? Review of General Psychology, 2(3), 300-319.

Gabriel, A. S., Lanaj, K., \& Jennings, R. E. (2020). Is one the loneliest number? A withinperson examination of the adaptive and maladaptive consequences of leader loneliness at work. Journal of Applied Psychology.

Gardner, W. L., Avolio, B. J., Luthans, F., May, D. R., \& Walumbwa, F. (2005). “Can you see the real me?" A self-based model of authentic leader and follower development. The Leadership Quarterly, 16(3), 343-372.

Gierveld, D. J., Tilburg, T., \& Dykstra, D. (2006). Loneliness and social isolation. In D. Perlman \& A. Vangelisit (Eds.), The Cambridge Handbook of Personal Relationships (pp. 485-500). Cambridge: Cambridge University Press.

Gooty, J., Connelly, S., Griffith, J., \& Gupta, A. (2010). Leadership, affect and emotions: A state of the science review. The Leadership Quarterly, 21(6), 979-1004.

Graen, G., \& Uhl-Bien, M. (1995). Relationship-based approach to leadership: Development of leader-member exchange (LMX) theory of leadership over 25 years: Applying a multi-level multi-domain perspective. The Leadership Quarterly, 6(2), 219-247.

Grijalva, E., \& Harms, P. D. (2014). Narcissism: An Integrative Synthesis and Dominance Complementarity Model. Academy of Management Perspectives, 28(2), 108-127.

Hawkley, L. C., Hughes, M. E., Waite, L. J., Masi, C. M., Thisted, R. A., \& Cacioppo, J. T. (2008). From social structural factors to perceptions of relationship quality and loneliness: the Chicago health, aging, and social relations study. The Journals of Gerontology Series B: Psychological Sciences and Social Sciences, 63(6), S375-S384.

Hedges, K. (2012). Do you feel lonely as a leader? Study says you're not alone. Forbes. Retrieved from http://www.forbes.com/sites/work-in-progress/2012/02/23/if-markzuckerberg-is-lonely-heres-my-solution/

Heinrich, L. M., \& Gullone, E. (2006). The clinical significance of loneliness: a literature review. Clinical Psychology Review, 26(6), 695-718. Retrieved from 
http://www.ncbi.nlm.nih.gov/pubmed/16952717

Holt-Lunstad, J., Smith, T. B., Baker, M., Harris, T., \& Stephenson, D. (2015). Loneliness and social isolation as risk factors for mortality: A meta-analytic review. Perspectives on Psychological Science, 10(2), 227-237.

House, J., Landis, K., \& Umberson, D. (1988). Social relationships and health. Science, 241(4865), 540-545.

Humphrey, R. H., Pollack, J. M., \& Hawver, T. (2008). Leading with emotional labour. Journal of Managerial Psychology, 23, 151-168.

Johnson, S. K. (2008). I second that emotion: Effects of emotional contagion and affect at work on leader and follower outcomes. The Leadership Quarterly, 19(1), 1-19.

Jung, H. S., Song, M. K., \& Yoon, H. H. (2021). The Effects of Workplace Loneliness on Work Engagement and Organizational Commitment: Moderating Roles of LeaderMember Exchange and Coworker Exchange. Sustainability, 13(2), 948.

Kahn, W. W. A. (1990). Psychological conditions of personal engagement and disengagement at work. Academy of Management Journal, 33(4), 692-724.

Kuna, S. (2019). All by myself? Executives' impostor phenomenon and loneliness as catalysts for executive coaching with management consultants. The Journal of Applied Behavioral Science, 55(3), 306-326.

Larsen, R., \& Diener, E. (1992). Promises and problems with the circumplex model of emotion. In M. S. Clark (Ed.), Review of personality and social psychology: Emotion and social behavior, vol. 114 (pp. 25-59). Newbury Park: Sage Publications.

Leary, M., Tambor, E., Terdal, S., \& Downs, D. (1995). Self-esteem as an interpersonal monitor: The sociometer hypothesis. Journal of Personality and Social Psychology, $68(3), 518-530$.

Li, N. P., \& Kanazawa, S. (2016). Country roads, take me home... to my friends: How intelligence, population density, and friendship affect modern happiness. British Journal of Psychology, 107(4), 675-697.

Lips-Wiersma, M., Wright, S., Wright, S., \& Dik, B. (2016). Meaningful work: differences among blue-, pink-, and white-collar occupations. Career Development International, $21(5), 534-551$.

Lord, R. G. (1985). An information processing approach to social perceptions, leadership and behavioral measurement in organizational settings. Research in Organizational Behavior, 7, 87-128.

Lord, R. G., \& Maher, K. J. (1991). Leadership and information processing: Linking perceptions and performance. London: Routledge.

Masi, C.M., Chen, H.Y., Hawkley, L.C., Cacioppo, J. T. (2011). A meta-analysis of interventions to reduce loneliness. Personality and Social Psychology Review, 15(3), 166.

Maslow, A. H. (1943). A theory of human motivation. Psychological Review, 50(4), 370-96. 
Menges, J. I., Walter, F., Vogel, B., \& Bruch, H. (2011). Transformational leadership climate: Performance linkages, mechanisms, and boundary conditions at the organizational level. Leadership Quarterly, 22(5), 893-909.

Mintzberg, H. (1973). The Nature of Managerial Work. New York: Harper \& Row.

Owens, B., \& Hekman, D. (2012). Modeling how to grow: An inductive examination of humble leader behaviors, contingencies, and outcomes. Academy of Management Journal, 55(4), 787-818.

Owens, B. P., Walker, A. S., \& Waldman, D. A. (2015). Leader narcissism and follower outcomes:The counterbalancing effect of leader humility. Journal of Applied Psychology, 100(4), 1-11.

Ozcelik, H., \& Barsade, S. G. (2018). No Employee an Island: Workplace Loneliness and Job Performance. Academy of Management Journal, 61(6), 2343-2366.

Page, R., \& Cole, G. (1991). Demographic predictors of self-reported loneliness in adults. Psychological Reports, 68, 939-945.

Peng, J., Chen, Y., Xia, Y., \& Ran, Y. (2017). Workplace loneliness, leader-member exchange and creativity: The cross-level moderating role of leader compassion. Personality and Individual Differences, 104, 510-515. https://doi.org/10.1016/j.paid.2016.09.020

Petriglieri, G. (2014). Why work is lonely. Harvard Business Review. Retrieved from https://hbr.org/2014/03/why-work-is-lonely

Podsakoff, P. M., MacKenzie, S. B., Lee, J.-Y., \& Podsakoff, N. P. (2003). Common method biases in behavioral research: a critical review of the literature and recommended remedies. The Journal of Applied Psychology, 88(5), 879-903.

Qualter, P., Vanhalst, J., Harris, R., Van Roekel, E., Lodder, G., Bangee, M., ... Verhagen, M. (2015). Loneliness across the life span. Perspectives on Psychological Science, $10(2), 250-264$.

Rajah, R., Song, Z., \& Arvey, R. D. (2011). Emotionality and leadership: Taking stock of the past decade of research. The Leadership Quarterly, 22(6), 1107-1119.

Rico-Uribe, L. A., Caballero, F. F., Olaya, B., Tobiasz-Adamczyk, B., Koskinen, S., Leonardi, M., ... Miret, M. (2016). Loneliness, social networks, and health: A crosssectional study in three countries. PloS One, 11(1), p.e0145264.

Russell, D., Peplau, L. a, \& Cutrona, C. E. (1980). The revised UCLA Loneliness Scale: Concurrent and discriminant validity evidence. Journal of Personality and Social Psychology, 39(3), 472-480.

Russell, J. a. (1980). A circumplex model of affect. Journal of Personality and Social Psychology, 39(6), 1161-1178.

Russell, J. A. (2003). Core affect and the psychological construction of emotion. Psychological Review, 110(1), 145-172.

Ryan, R. M., \& Deci, E. L. (2002). Overview of self-determination theory: An organismic 
dialectical perspective. Handbook of Self-determination Research, 2, 3-33.

Saporito, T. (2012). It's Time to Acknowledge CEO Loneliness. Harvard Business Review. Retrieved from https://hbr.org/2012/02/its-time-to-acknowledge-ceo-lo/

Selznick, P. (1957). Leadership in Administration: A Sociological Interpretation. Evanston, IL: Pew, Peterson, and Co.

Shamir, B., House, R., \& Arthur, M. (1993). The motivational effects of charismatic leadership: A self-concept based theory. Organization Science, 4(4).

Shaver, P., Schwartz, J., Kirson, D., \& O’Connor, C. (1987). Emotion knowledge: Further exploration of a prototype approach. Journal of Personality and Social Psychology, 52(6), 1061-1086.

Silard, A. (2020). Screened In: The Art of Living Free in the Digital Age. Inner Leadership Press.Silard, A., \& Wright, S. (2020). The price of wearing (or not wearing) the crown: The effects of loneliness on leaders and followers. Leadership, 16(4), 389-410.

Silard, A., \& Watson-Manheim, M. B. (2015). The bait-and-switch of the Internet: The influence of connectivity on contactedness and connectedness. In Conference Proceedings of the Academy of Management. Vancouver, Canada: Academy of Management.

Sosik, J. J., \& Dinger, S. L. (2007). Relationships between leadership style and vision content: The moderating role of need for social approval, self-monitoring, and need for social power. The Leadership Quarterly, 18(2), 134-153.

Spreitzer, G. M. (1995). Psychological empowerment in the workplace: Dimensions, measurement and validation. Academy of Management Journal, 38(5), 1442-1465.

Stephens, J., Heaphy, E., \& Dutton, J. (2011). High quality connections. In K. Cameron \& G. Spreitzer (Eds.), Handbook of Positive Organizational Scholarship. New York: Oxford University Press.

Tam, K. Y., \& Chan, C. S. (2019). The effects of lack of meaning on trait and state loneliness: Correlational and experience-sampling evidence. Personality and Individual Differences, 141, 76-80.

Toegel, G., Kilduff, M., \& Anand, N. (2013). Emotion helping by managers: An emergent understanding of discrepant role expectations and outcomes. Academy of Management Journal, 56(2), 334-357.

Wang, D., \& Liu, H. (2020). Effects of job autonomy on workplace loneliness among knowledge workers. Chinese Management Studies.

Waytz, A., Chou, E. Y., Magee, J. C., \& Galinsky, A. D. (2015). Not so lonely at the top: The relationship between power and loneliness. Organizational Behavior and Human Decision Processes, 130, 69-78.

Wegge, J., Van Dick, R., \& von Bernstorff, C. (2010). Emotional dissonance in call centre work. Journal of Managerial Psychology, 25(6), 596-619.

Williams, K., Cheung, C., \& Choi, W. (2000). Cyberostracism: Effects of being ignored over 
the Internet. Journal of Personality and Social Psychology, 79(5), 748-762.

Winnicott, D. W. (1960). The theory of the parent-infant relationship. International Journal of Psychoanalysis, 41(6), 585-595.

Wright, S. (2012). Is it lonely at the top? An empirical study of managers' and nonmanagers' loneliness in organizations. The Journal of Psychology, 146(1-2), 47-60.

Wright, S., \& Silard, A. (2020). Unravelling the antecedents of loneliness in the workplace. Human Relations, online first.

Yammarino, F. J., Spangler, W. D., \& Bass, B. M. (1993). Transformational leadership and performance: A longitudinal investigation. Leadership Quarterly, 4(1), 81-102. 
TABLE 1.

Means and standard deviations for leaders and employees on relationship quality measures, meaningfulness, and loneliness

\begin{tabular}{llllllllllll}
\hline Group & $\mathrm{N}$ & $\begin{array}{l}\text { Emotional } \\
\text { Connection }\end{array}$ & $\begin{array}{l}\text { Positive } \\
\text { Regard }\end{array}$ & Mutuality & Meaning & Loneliness \\
\hline & & Mean & SD & Mean & SD & Mean & SD & Mean & SD & Mean & SD \\
\hline Leader & 28 & 3.25 & 1.08 & $3.73^{*}$ & .51 & $3.78^{*}$ & .46 & $4.44^{*}$ & .48 & 2.02 & .43 \\
Follower & 235 & $3.70^{*}$ & 1.01 & 3.34 & .70 & 3.45 & .68 & 4.04 & .48 & 2.15 & .42 \\
$* p<0.05$ & & & & & & & & & & & \\
$*$
\end{tabular}


TABLE 2

Correlation Matrix among relationship quality, loneliness and meaningfulness variables for leaders $(N=28)$

\begin{tabular}{|c|c|c|c|c|c|}
\hline Variables & $\begin{array}{l}\text { Emotional } \\
\text { Connection }\end{array}$ & $\begin{array}{c}\text { Positive } \\
\text { Regard }\end{array}$ & Mutuality & Loneliness & Meaningfulness \\
\hline $\begin{array}{l}\text { Emotional } \\
\text { Connection }\end{array}$ & 1 & & & & \\
\hline Positive Regard & .02 & 1 & & & \\
\hline Mutuality & .08 & $.72 * *$ & 1 & & \\
\hline Loneliness & $-.23 *$ & -.11 & -.11 & 1 & \\
\hline Meaningfulness & .25 & .06 & .20 & -.03 & 1 \\
\hline
\end{tabular}


TABLE 3

Correlation Matrix among relationship quality, loneliness and meaningfulness variables for employees $(N=235)$

\begin{tabular}{|c|c|c|c|c|c|}
\hline Variables & $\begin{array}{l}\text { Emotional } \\
\text { Connection }\end{array}$ & $\begin{array}{c}\text { Positive } \\
\text { Regard }\end{array}$ & Mutuality & Loneliness & Meaningfulness \\
\hline $\begin{array}{c}\text { Emotional } \\
\text { Connection }\end{array}$ & 1 & & & & \\
\hline Positive Regard & .08 & 1 & & & \\
\hline Mutuality & $.25^{*}$ & $.67 * *$ & 1 & & \\
\hline Loneliness & $-.38 * *$ & -.18 & $-.23 *$ & 1 & \\
\hline Meaningfulness & .19 & .14 & .18 & -.09 & 1 \\
\hline
\end{tabular}




\section{TABLE 4}

Regression analyses predicting loneliness in employees

\begin{tabular}{llll}
\hline Variable & $B$ & SE & $\bullet$ \\
\hline Emotional & -.37 & .15 & $-.48^{*}$ \\
Connection & & & \\
Positive Regard & -.20 & .27 & -.18 \\
Mutuality & -.51 & .23 & $-.54^{*}$ \\
Meaningfulness & -.19 & .22 & -.16 \\
$R 2$ & & .46 & \\
$F$ & & $2.93^{*}$ & \\
$* p<.01$ & &
\end{tabular}


